\title{
A REVIEW OF MECHANICAL MOVE SPRINKLER IRRIGATION CONTROL AND AUTOMATION TECHNOLOGIES
}

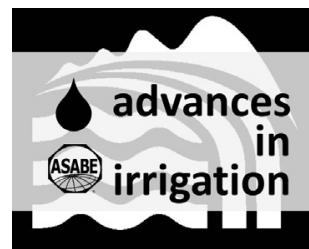

\author{
W. L. Kranz, R. G. Evans, F. R. Lamm, S. A. O’Shaughnessy, R. T. Peters
}

\begin{abstract}
Electronic sensors, equipment controls, and communication protocols have been developed to meet the growing interest in using center pivot and lateral move irrigation systems to deliver different irrigation depths to management zones based on previous production levels, soil texture, or topography. Onboard and field-distributed sensors can collect data necessary for real-time irrigation management decisions and transmit the information directly or through wireless networks to the main control panel or base computer. Equipment controls necessary to alter water application depth to meet the management criteria for relatively small management zones are now commercially available from irrigation system manufacturers and after-market suppliers. Communication systems such as cell phones, satellite radios, and internet-based systems are also available and allow the operator to query the main control panel or base computer from any location at any time. Selection of the communications system for remote access depends on local and regional topography and cost relative to other methods. Recent developments in the center pivot sprinkler industry have led to contractual relationships between after-market suppliers and irrigation system manufacturers that should support further development of technologies necessary to improve the management of water, nutrient and pesticide applications. Although the primary focus of this article is center pivot sprinkler irrigation, much of the discussion could also apply to lateral move sprinkler irrigation systems.
\end{abstract}

Keywords. Center pivot sprinkler, Distributed sensor networks, Site-specific irrigation, Variable rate irrigation, Wireless communication.

A gricultural fields are variable in terms of crop production for many reasons, including topographic relief, changes in soil texture, tillage and compaction, fertility differences, and localized pest distributions. The effects of different sources of variability on management can be additive and interrelated. Fortunately, recent advances in communications and microprocessors have enabled the general implementation of site-specific water applications by self-propelled center pivot and lateral move sprinkler irrigation systems.

The design of an irrigation system suitable for varying water application spatially based on a series of data inputs

Submitted for review in August 2011 as manuscript number SW 9313; approved for publication by the Soil \& Water Division of ASABE in March 2012. Presented at the 5th Decennial Irrigation Symposium as Paper No. 9632-IRR10.

The authors are William L. Kranz, ASABE Member, Associate Professor, University of Nebraska, Concord; Robert G. Evans, ASABE Fellow, Supervisory Research Agricultural Engineer, USDA-ARS, Sidney, Montana; Freddie R. Lamm, ASABE Member, Professor, Kansas State University, Colby; Susan A. O'Shaughnessy, ASABE Member, Agricultural Engineer, USDA-ARS, Bushland, Texas; and R. Troy Peters, ASABE Member, Assistant Professor, Washington State University, Prosser. Corresponding author: William L. Kranz, University of Nebraska, 57905866 Road, Concord, NE 68728; phone: 402-584-3857; e-mail: wkranz1@unl.edu. can be complex because of the need to address and integrate constraints imposed by the field site, irrigation system capabilities, and producer management. The field site constraints may be the most difficult to address because they may be numerous and may be exhibited in varying extents from year-to-year. Often, the underlying cause of crop performance variation is not fully understood. Extreme fieldto-field variability further compounds selection of appropriate irrigation system capabilities required to achieve the desired objective. The general management philosophy and operational preferences of the owner/operator must also be addressed through the use of decision support systems (DSS). These issues are discussed in detail by Buchleiter et al. (2000), Evans et al. (2000), Sadler et al. (2000), Perry et al. (2004), Sadler et al. (2005), and McCarthy et al. (2010). McCarthy et al. (2010) developed a predictiveadaptive control model (VARIwise) for site-specific irrigation water application of cotton using a center pivot sprinkler, concluding that although the framework accommodated a range of system control strategies, further work was necessary for using data with a range of spatial and temporal scales.

Decision support systems should provide a holistic and robust approach to irrigated crop management. After the irrigator defines the decision criteria and management 
guidelines to be used within the field, DSS must implement the approach through software and microprocessor-based control systems. Results of geo-referenced grid sampling of soils, yield maps, and other precision agriculture tools can be major components in defining rules for these management systems. These "rules" are used as the basis for analysis and interpreting data from real-time data networks, remote sensing, irrigation monitoring systems, agronomic, and other information used to provide direction and implement basic commands. Decision support systems can also include instructions for chemigation (e.g., nitrogen fertilizer or pesticides) and provide alerts (e.g., insects, diseases) to the grower based on output from established models using real-time environmental data. In essence, DSS provide more management flexibility by implementing near term, routine commands to direct irrigation schedules and other basic operations, which frees the irrigator to concentrate on other management activities.

Successful DSS will require the integration of various sensor systems (on the irrigation system and within the field), irrigation system hardware and controllers to manage sprinkler application and hydraulics, accurate determination of field position (e.g., GPS), and ample computer processing speed and power. The maximum benefits will be derived when DSS respond to actual crop conditions. Crop conditions can be estimated from field-based or remotelysensed plant measurements (e.g., crop canopy temperature), or inferred from soil water measurements or crop evapotranspiration estimates. Ideally, the most robust monitoring system will be an integration of multiple approaches.

General, broad-based, and easily modified software for managing these DSS for a multitude of crops, climatic conditions, topography, and soil textures are not currently available from manufacturers, government agencies, or consultants. Development and updating of management maps for these irrigation systems based on soils, soil water sensors, yield, or water availability is a highly specialized process that is currently done only once a year or less. However, widespread implementation will require userfriendly data input capabilities that allow management maps to be adjusted much more frequently.

The objectives of this article are to provide a general discussion of the progression of sprinkler control and monitoring technologies to include: wireless sensor networks and communication protocols; available sensors and data management schemes; remote access for irrigation systems; their network and communication requirements; available sensors and data management schemes; and the current status of commercially available monitoring and control systems.

\section{SPRINKLER CONTROL OPTIONS}

Mechanically-moved sprinkler irrigation systems, such as center pivot sprinklers and lateral move sprinklers, in current usage have a wide range of drive technologies (e.g., water, electric, and oil hydraulic motors). These irrigation systems often operate on fields having both variable topography and soil textures. In-field soil variability issues such as low water holding capacity or low infiltration rates present significant challenges to managers in decisions about how much water to apply to various areas of the field. Each of these factors represents a reason for using some sort of monitor/controller to manage water applications based upon need. Precision application, variable rate irrigation, and site-specific irrigation are terms developed to describe water application devices with the goal of maximizing the economic and/or environmental value of the water applied via a moving irrigation system.

Probably, the earliest center pivot sprinkler control was the methodology to alter the water application depth by mechanical adjustment of the speed of lateral travel. Additional early developments provided a very limited set of controls to turn end guns on and off and to stop the center pivot sprinkler operation based on field position or completion of the irrigation cycle (e.g., edge-of-field stops and stop-in-slot controls). The development of programmable control panels allowed the speed of sprinkler travel to be adjusted multiple times during an irrigation event. This approach was often used by producers when portions of the field were planted to a different crop, but these control panels generally lacked the flexibility necessary to supply water at rates required to meet the management objectives of relatively small field areas with irregular-shaped boundaries. In the past few years, some companies have begun marketing control panels with an option to change irrigation system pivot travel speed in very small increments ranging from $<1^{\circ}$ to $10^{\circ}$ as the lateral rotates around the field. This tactic effectively changes application depths in each defined radial sector of the field, and generally no additional hardware is needed. This technique is commonly referred to as speed or sector control, but could also be referred to as variable depth irrigation. Nevertheless, field variability seldom occurs in long, narrow pie-slice shaped parcels (fig. 1) and because the sprinkler packages apply the same depth along the entire lateral length, adjusting speed of rotation may not provide a sufficient level of water application control.

A number of methods have been under development to address varying application depths along the moving lateral. A variable flow sprinkler was developed for controlling irrigation water application by King and Kincaid (2004) at Kimberly, Idaho. The variable flow sprinkler uses a mechanically-activated pin to alter the nozzle orifice area which adjusts the sprinkler flow rate over the range of $35 \%$ to $100 \%$ of its design flow rate based on operating pressure. The pin was controlled using either electric or hydraulic actuators. The main concern with this approach is that the wetted pattern and water droplet size distribution of the sprinkler changed with flow rate which created water application uniformity issues due to a change in sprinkler pattern overlap.

Changes in water application depth can also be accomplished by using a series of on-off time cycles or "pulsing" individual or groups of sprinklers (Karmeli and Peri, 1974). Management of the on-off time of sprinklers can be used to manage the time-averaged water application rate. Later efforts in Washington State involved equipping a center 


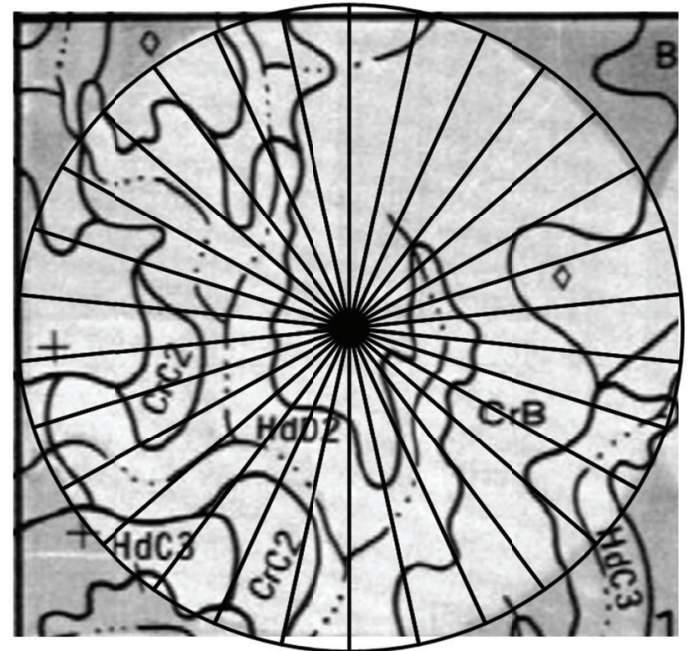

Figure 1. Schematic diagram showing a soil survey map overlain by center pivot speed of travel settings changed every $12^{\circ}$ or in 30 locations during a single revolution.

pivot sprinkler with a custom-built electronic controller to activate water operated solenoid valves in groups or banks of 2 to 4 sprinkler nozzles (Evans et al., 1996; Evans and Harting, 1999). The use of normally-open solenoids protected the irrigation system from damage and ensured irrigation water was applied even if the control system failed.

Precise and accurate control of irrigation using a series of in-field and onboard wireless monitoring spread spectrum radios/sensors networks that pulsed individual sprinkler solenoid valves according to prescription maps was reported by Chávez et al. (2010 a,b,c). In this research with two different lateral move systems, deviations related to positioning of sprinklers when irrigating were on average $2.5 \pm 1.5 \mathrm{~m}$ due mainly to the accuracy of the digital global positioning systems (DGPS). This level of accuracy is a vast improvement over systems not equipped with a GPS of any kind.

Controlling irrigation water application depth has also been accomplished through the use of multiple manifolds, each with different sized sprinkler nozzles to vary water and nitrogen application (Lyle and Bordovsky, 1981; Roth and Gardner, 1989, Camp et al., 1998). These systems often included two to three manifolds where simultaneous activation of one or more solenoid valves controlling individual manifolds adjusted the water application rate and depth. When individual or groups of sprinkler nozzles are managed by on-off cycles or use the multiple manifolds, an irrigation system is termed to use zone control for sprinkler applications. Zone control involves spatially defining irregularly-shaped management zones following specific guidelines (e.g., guidelines developed from crop yield maps and rationale for yield differences, different soil characteristics, field topography variations, rock outcroppings, etc.), and differentially applying water to each management zone. Most zone control systems vary water application depths by various forms of pulse modulation (on-off cycling of spraytype sprinkler nozzles or groups of nozzles) for a given irrigation system speed, but zone control systems could potentially be combined with aspects of speed control to better balance water flow rates provided to the irrigation system. Although the previously discussed speed control techniques are the most common site-specific sprinkler irrigation systems in use today, zone control systems probably have the largest potential for achieving the most efficient and economically viable management of water and energy.

Current uses of site specific, variable rate irrigation (SSVRI, i.e., speed or zone control technologies) on agricultural fields are generally on a fairly coarse scale. Probably the most common use is limited to site-specific treatment of complex shaped, non-cropped areas such as waterways, ponds, roads, drainage ways, or rocky outcrops where some sprinkler nozzles are turned off. However, SS-VRI also has application for animal production systems that wish to use the center pivot to apply liquid animal waste to field areas where there are legally required setbacks from wells, surface water impoundments, or other areas. Similarly, setbacks may be required to meet water quality protection goals such as minimizing nitrate leaching or contamination of wildlife areas. In these situations, normal cost recovery based on crop yield may be of secondary importance due to the potential for savings in product application cost.

Two main approaches to SS-VRI sprinkler controls (block or individual sprinkler) can have advantages and disadvantages depending on the desire to match infield management zones. For example, the map presented in figure $2 \mathrm{a}$ is based strictly upon the soil mapping units presented in figure 1 . If the water management zones were defined strictly based on soil mapping units, grouping three to five sprinklers (indicated by the rectangular shape) together in blocks along the lateral might fit the contour at Position A quite precisely. At Position B, since the grouping of sprinklers is fixed by the original installation, the same three to five sprinklers may need to irrigate more than one management zone. Thus, the attempt to match water application depths to contour-shaped management zones using blocks of sprinklers may limit the number of effective management zones within a field.

The second approach is to control each individual sprinkler along the lateral independently. Figure $2 \mathrm{~b}$ presents the same map as in figure $2 a$. The difference is that as the lateral travels around the pivot point individual sprinklers can be controlled in groups based on field position not on system plumbing. At Position A, the same sprinklers included in blocks shown in figure 2 a may be controlled as a block of individual sprinklers in figure $2 \mathrm{~b}$. At Position B, a completely different sets of sprinklers can be combined together to match the zone contour at that location as precisely as was obtained at Position A.

The use of block or individual sprinkler types of control leads to areas of transition parallel and perpendicular to the travel direction of the irrigation machine. The area impacted by the transition from one management zone to another is directly related to the wetted radius of the sprinklers installed on the system and the distance from the pivot point. Although, several adjacent sprinklers may contribute to the application pattern and this may result is some application irregularities at various points of overlap, transition zones are more likely to conform to gradual changes in 


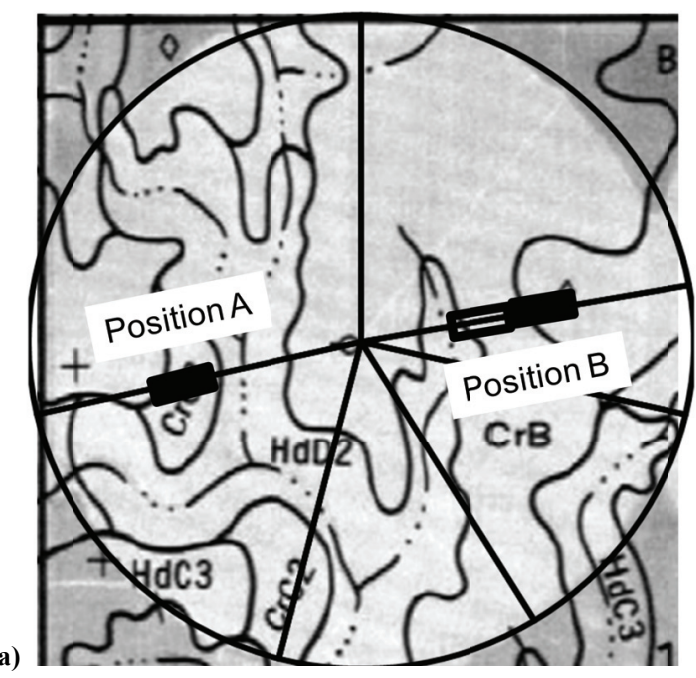

(b)

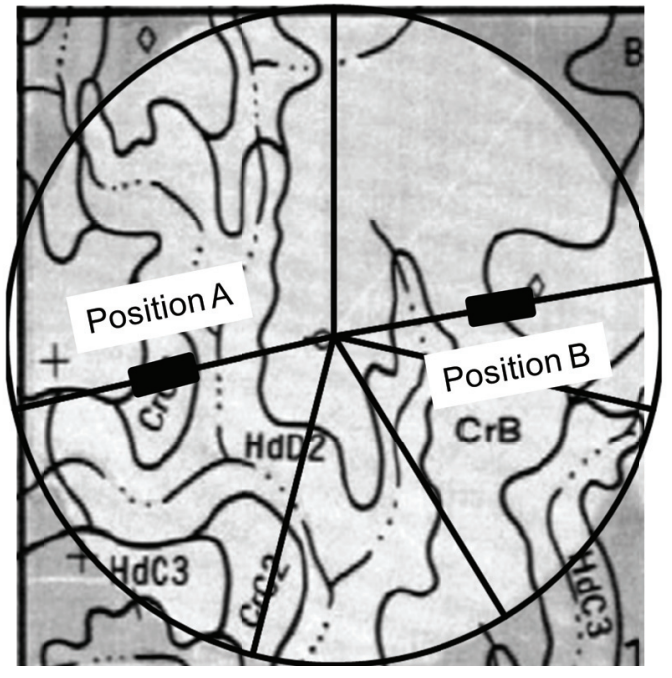

Figure 2. Schematic drawings of a soil survey map showing the implementation of the sprinkler block (a) and individual sprinkler (b) control approach to SS-VRI.

field conditions such as soil texture, topography, or soil physical properties. Consequently, implementation of management zones and the evaluation of the impact of changes in application must be undertaken with the knowledge that the change is not instantaneous in space but rather a gradual transition from one zone to another.

The potential impacts of implementing these two approaches has yet to be documented in the field and likely will depend on the level of variation exhibited within management zones. However, if the desire is to precisely match variable-sized and shaped management zones, the approach with the maximum amount of flexibility in sprinkler control would be best able to capitalize on the field-based information used in developing the management zone map. With sprinkler spacing ranging from 2 to $6 \mathrm{~m}$, the magnitude of the difference in terms of crop area depends on the distance from the pivot point. Further, it is anticipated that individual sprinkler controls will require additional components that will potentially increase maintenance requirements in the long run.

One of the largest factors limiting the use of SS-VRI is cost, often ranging from $\$ 2000$ for a system monitor to over $\$ 20,000$ for control of individual sprinklers along the entire system length. In some cases, producers are treating symptoms of low crop production such as leaf yellowing, leaf curling, and stunted plants by substituting SS-VRI technology when improved management of other inputs might be more beneficial in improving crop production and water use efficiency at a lower overall cost.

\section{DisTRIBUTED NETWORKS AND Communication Protocols}

Site-specific variable-rate irrigation management allows producers to maximize their productivity while conserving water (Sadler et al., 2005). However, the seamless integration of sensors, data interface, software design, and communications for SS-VRI control using wireless sensorbased irrigation systems can be challenging (King et al.,
2000). Researchers have addressed the issues of interfacing sensors and irrigation control using several approaches. Shock et al. (1999) used radio transmission for soil water data from in-field data loggers to a central data management site where decisions were made and manually changed by the operator. Miranda et al. (2003) used a closed-loop control system and determined irrigation amount based on distributed soil water measurements. Wall and King (2004) explored various designs for smart soil water sensors and sprinkler valve controllers for implementing "plug-and-play" technology, and proposed architectures for distributed sensor networks for SS-VRI irrigation automation (King and Wall, 1998). They concluded that the coordination of control and instrumentation data is most effectively managed using data networks and low-cost microcontrollers.

Adopting a standard interface for sensors and actuators allows reuse of common hardware and communication protocols such as communication interface and control algorithm software. Instrumentation and control standards for RS232 serial (voltage based) and RS485 (current based) communication protocols have been widely applied and well documented for integrating sensors and actuators, particularly in industrial applications. However, these systems require direct wire connections to transmit data between the control panel or microprocessor and the sensors or actuators. The need for direct connection between the control and data acquisition systems poses a problem when applied to pivot irrigation systems due to the potential for damage and the cost of installation.

Wireless network systems are an alternative to hardwired systems for data transport and have been used for infield sensor network systems. Two wireless protocols that eliminate the need for direct wire connections are Bluetooth (802.15.1) (IEEE Std. 802.15.1, 2005) and ZigBee (802.15.4) (IEEE Std. 802.15.4a, 2007). Bluetooth and ZigBee (IEEE 802.11 standards) are designed for radiofrequency (RF) telemetry applications that support a relatively low data rate, and provide solutions for long battery life and good network security. ZigBee is a low-cost, 
nonproprietary wireless mesh networking standard, which allows longer life with smaller batteries, and the directsequence spread spectrum mesh networking provides high reliability. Bluetooth is a faster but more expensive standard than ZigBee and uses spread spectrum modulation technology called frequency hopping to avoid interference and ensure data integrity. ZigBee has lower power needs than Bluetooth, but it also transmits effectively over less distance (e.g., $30 \mathrm{~m}$ ). Enhanced Bluetooth transmitters are available that can transmit up to $1 \mathrm{~km}$.

Bluetooth wireless technology has been adapted in sensing and control of agricultural systems (Lee et al., 2002; Oksanen et al., 2004; Zhang, 2004; Kim et al., 2008; Kim and Evans, 2009). Zhang (2004) evaluated Bluetooth radio in different agricultural environments, power consumption levels, and data transmission rates. He observed $1.4 \mathrm{~m}$ as an optimal radio height for maximum 44-m radio range and reported limitations of significant signal loss after $8 \mathrm{~h}$ of continuous battery operation and 2 to $3 \mathrm{~s}$ of transmission latency with the increase of communication range. Oksanen et al. (2004) used a PDA with Bluetooth to connect a GPS receiver for their open, generic, and configurable automation platform for agricultural machinery. Lee et al. (2002) explored an application of Bluetooth wireless data transportation of moisture content of harvested silage and reported a limitation of 10-m short range. However, the limitations of Bluetooth applications in agricultural systems can be solved or minimized by system design optimization. The power shortage can be solved by using solar power that recharges the battery. The radio range and transmission latency can also be extensively improved by using an upgraded power class and antenna. These same techniques can be applied to Zigbee-based systems.

Drawbacks in using wireless sensors and wireless sensor networks include provision for ample bandwidth, existing inefficiencies in routing protocols, electromagnetic interference, interference by vegetation, radio range, sensor battery life (Zhang, 2004), and synchronous data collection (Dowla, 2006). An immediate limiting factor in selfpowered wireless sensor network (WSN) operation is battery life, which can be addressed to some degree by decreasing the duty cycle of the sensor nodes, which is typically a significant method for improving battery longevity (Hebel, 2006). Power needs are often mitigated by using solar panels. Other identified challenges specific to WSNs and agriculture include interference with radio propagation due to crop canopy height (Goense and Thelen, 2005). Signal obstruction issues relating to crop height and in-field equipment are inherently reduced when the moving sprinkler is used as the sensor platform; but infield sensors require manual adjustment above crop canopy.

In row crop production systems, the need to install and retrieve the sensors, data loggers, and radio transmission equipment from each measurement site on an annual basis requires trained labor to ensure the equipment is handled, installed and removed properly. Few producers possess the knowledge base necessary and rarely hire personnel who could perform these tasks reliably. Consequently, future developments in wireless technology will need to include the semi-permanent and below-ground installation of sensors and transmission equipment. The addition of this requirement will require the development of WSNs with extended communication range (both in air and in soil) and battery life sufficient to limit the replacement frequency to the level required to gain acceptance by center pivot managers.

\section{SENSORS AND INTEGRATED DATA MANAGEMENT SCHEMES}

One of the earliest and basic uses of sensors on a center pivot for management purposes was to determine alignment and lateral position. Until recently, control systems based on the digital angle resolver typically had an accuracy of $\pm 0.5^{\circ}$ to $1.5^{\circ}$ of the first tower position. Peters and Evett (2005) found that resolver-determined position errors could be as great as $5^{\circ}$ or over $30 \mathrm{~m}$ on a $390-\mathrm{m}$ system. Consequently, many center pivot sprinkler manufacturers now employ a Wide-Area Augmentation System (WAAS) enabled GPS antenna option to identify the position of the end tower to an accuracy of less than $3 \mathrm{~m}$. With the WAAS enabled GPS antenna, accuracy of the outside tower position of less than $1 \mathrm{~m}$ can often be obtained because the long duration start-stop cycles of the system allow further buffering of GPS errors. The net effect of being able to accurately determine the lateral location is that management zone size can be reduced without increasing the potential for a misapplication of water, nutrients, or pesticides.

Recent innovations in communication technologies combined with advances in internet technologies offer tremendous opportunities for development and application of real-time management systems for agriculture (Beckwith et al., 2004; Camilli et al., 2007; Liang et al., 2007; Coates and Delwiche, 2008; Kim et al., 2007, 2008; Pierce and Elliot, 2008; Vellidis et al., 2008). It is anticipated that DSS will increasingly rely on WSNs for real-time, automated recording of micro-meteorological instrumentation, or other sensors that are strategically distributed to provide continuous feedback of field conditions to center pivot control panels and field managers. Sensors mounted on the irrigation lateral also can be used to provide real-time feedback for decision support as the system moves across a field (Peters and Evett, 2008; O'Shaughnessy and Evett, 2010). Field-based data may also be integrated with various remotely sensed data to help differentiate between biotic and abiotic stresses.

Integrated data sources and networks provide needed information to recalibrate and check various simulation model parameters for on-the-go irrigation scheduling and adjustments (Andrade-Sanchez et al., 2007; Kim et al., 2007, 2008; Kim and Evans 2009; O'Shaughnessy and Evett, 2010). Integration of these technologies into DSS can help determine when, where, and how much water to apply in real time, enabling implementation of advanced water conservation measures that can simultaneously address economic viability, crop production with limited water supplies, energy conservation, and enhanced environmental benefits. 
Satellite and aerial imagery, GIS mapping services, and GPS are becoming commonplace throughout the agricultural industry around the world. Remotely sensed information can be photometric (visible), thermal, or multispectral and can be acquired by aircraft and satellites in a variety of formats and resolutions. Multispectral data can be used to enhance water and energy conservation by helping to determine the causes of the non-uniform crop appearance and yield (Gowda et al., 2008, Hornbuckle et al., 2009). Advanced pattern-recognition software and other tools for multispectral or other remotely sensed data can be used to detect many problems in agriculture. However, two barriers to the widespread adoption and use of these integrated technologies are the present cost of these services and the difficulty for producers to understand and use the output in a timely manner. The timeliness of this type of information is critical to producers because it is much better for their farm profitability if they can make adjustments as the problems develop, not after the fact. New analysis tools and interpretation aids as part of comprehensive DSS are needed for producers to take full advantage of these technologies.

Spectral and thermal ground-based remote sensors mounted on mechanical-move irrigation systems are capable of providing information to farmers in a timelier manner than aircraft or satellite sources. Infrared thermocouple thermometers mounted on a moving lateral can provide radiometric temperature measurements of in-field crop canopies. Software to control mechanical-move sprinkler systems has been integrated with this plant-feedback information and the Time-Temperature-Threshold (TTT) algorithm, patented as the Biologically Identified Optimal Temperature Interactive Console (BIOTIC) for managing irrigation by the USDA under Patent No. 5539637 (BIOTIC, Upchurch et al., 1996). Briefly, the TTT technique can be described as comparing the accumulated time that the crop canopy temperature is greater than a cropspecific temperature threshold with a specified critical time developed for a well-watered crop in the same region. The TTT technique has been used in automatic irrigation scheduling and control of plant water use efficiency for corn in drip irrigated plots, and soybean and cotton in LEPA irrigated plots (Evett et al., 1996, 2006; Lamm and Aiken, 2008; Peters and Evett, 2008; O'Shaughnessy and Evett, 2010). Peters and Evett $(2004,2007)$ demonstrated that remote canopy temperatures could be predicted from a contemporaneous reference temperature and a pre-dawn temperature measurement. Infrared canopy temperature measurements made from a mechanical-move sprinkler system can then be used to develop spatial and temporal temperature maps that correspond to in-field water stress levels of crops.

Many electromagnetic soil water sensors based on soil bulk dielectric permittivity are available (Evett et al., 2010) and can be incorporated into DSS for center pivot sprinkler irrigation systems. Many resistance-based sensors (commonly referred to as gypsum blocks or granular matrix sensors) are also available and could also be used with DSS. Recent discussions of these types of sensors, their accuracy and suitability for specific conditions have been provided by Evett et al. (2010) and Chávez et al. (2011).

Integration of information collected at varying frequencies and spatial scales into DSS will be necessary to utilize all sources of information available for making improved irrigation management decisions. The VARIwise model developed by McCarthy et al. (2010) is a recent example of how data collected from a variety of sources can be incorporated into a DSS to manage center pivot water applications. The Smart Crop system developed by Mahan et al. (2010) is a recent commercial example of an in-field wireless system for canopy temperature monitoring. Further development of this kind of management tool will be critical to the commercialization of DSS in the future.

\section{REMOTE COMMUNICATIONS WITH IRRIGATION SYSTEMS}

Recent developments in the center pivot sprinkler industry have resulted in contractual arrangements with developers of after-market control and monitoring systems. Categorical services provided include monitoring, control, communication systems for remote access, and data collection and reports to help summarize irrigation system performance, water and chemical applications, and ancillary data (table 1). Of the five major manufacturers of center pivot and lateral move systems, all provide remote monitoring and control of position, speed of travel, water "on or off " status, programmable stop and restart by position, and auxiliary components. The number of type of auxiliary control items differs by manufacturer. The benefits of remote monitoring for farmers are that they save time and fuel from driving out to fields where the irrigation systems are operating as expected.

All of the manufacturers provide guidance systems and some level of SS-VRI management (listed as maximum center pivot points and sprinkler application zones under the category of control). Manufacturers also have the technical expertise on staff to provide the necessary equipment for remote system access. Communication via cell phone allows a farmer to monitor multiple center pivots from any location, while RF communication and web-based posting provide the advantage of data overview and may help in making long-term decisions. Successful implementation of advanced automation for mechanically-moved systems will depend on the integration of real-time automated data collection and hardware control capabilities. Prices for the equipment vary among manufacturers and according to the amount of upgrades needed to satisfy the unique needs of each farmer and the amount of variability in each field. Frequently, this equipment and services can be retrofitted onto existing pivot systems, in addition to being purchased for new installations.

\section{CONClusions}

Electronic sensors, equipment controls, and communication protocols have been developed to meet the growing 
Table 1. Monitor, control, communication and data reporting capability of center pivot sprinkler control panels.

Center Pivot Sprinkler Manufacturer

Pierce Reinke T-L Valmont Zimmatic

Monitors

\begin{tabular}{|c|c|c|c|c|c|}
\hline $\begin{array}{l}\text { Position in field and travel } \\
\text { direction }\end{array}$ & $\mathrm{Y}$ & $\mathrm{Y}$ & $\mathrm{Y}$ & $\mathrm{Y}$ & $\mathrm{Y}$ \\
\hline Speed of travel & $\mathrm{Y}$ & $\mathrm{Y}$ & $\mathrm{Y}$ & $\mathrm{Y}$ & $\mathrm{Y}$ \\
\hline Wet or dry operation & $\mathrm{Y}$ & Y & $\mathrm{Y}$ & $\mathrm{Y}$ & $\mathrm{Y}$ \\
\hline Pipeline pressure & $\mathrm{Y}$ & $\mathrm{Y}$ & $\mathrm{Y}$ & $\mathrm{Y}$ & $\mathrm{Y}$ \\
\hline Pump status & $\mathrm{Y}$ & $\mathrm{Y}$ & Y & $\mathrm{Y}$ & $\mathrm{Y}$ \\
\hline Auxiliary components ${ }^{[\mathrm{a}]}$ & $Y(4)$ & $Y(7)$ & $Y(2)$ & $Y(6)$ & $Y(5)$ \\
\hline Stop-in-slot and auto restart & $\mathrm{Y}$ & $\mathrm{Y}$ & $\mathrm{Y}$ & $\mathrm{Y}$ & $\mathrm{Y}$ \\
\hline Wind speed & $\mathrm{Y}$ & $\mathrm{Y}$ & $\mathrm{N}$ & $\mathrm{Y}$ & $\mathrm{Y}$ \\
\hline
\end{tabular}

Controls

$\begin{array}{lllllll}\text { Start and stop } & \text { Y } & \text { Y } & \text { Y } & \text { Y } & \text { Y }\end{array}$

$\begin{array}{lllllll}\text { Speed of travel } & Y & Y & Y & Y & Y\end{array}$

$\begin{array}{llllll}\text { Auto restart and auto reverse } & Y & Y & Y & Y & Y\end{array}$

$\begin{array}{lllllll}\text { End gun operation } & Y & Y & Y & Y & Y\end{array}$

$\begin{array}{lllllll}\text { High and low pressure } & \text { Y } & \text { Y } & \text { Y } & \text { Y } & \text { Y }\end{array}$ shutdown

$\begin{array}{llllll}\text { High and low voltage } & \text { N/Y } & \text { N/Y } & \text { N/Y } & \text { Y/Y } & \text { Y/Y }\end{array}$ shutdown $^{[\mathrm{b}]}$

System stall shutdown

$\begin{array}{lllll}\mathrm{Y} & \mathrm{Y} & \mathrm{Y} & \mathrm{Y}\end{array}$

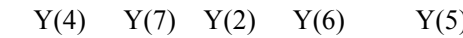

$\begin{array}{lllllll}\text { System }_{\text {guidance }}{ }^{[\mathrm{c}]} & \mathrm{Y} & \mathrm{Y} & \mathrm{Y} & \mathrm{Y} & \mathrm{Y}\end{array}$

$\begin{array}{llllll}\text { Maximum control points per } & 180 & 3600 & 180 & 180 & 180\end{array}$ circle $^{[\mathrm{d}]}$

$\begin{array}{llllll}\text { Sprinkler application } & 8 & 2 & 3 & 30 & \text { No Limit }\end{array}$

$\frac{\text { zones }^{[\mathrm{e}]}}{\text { Remote Communications }}$

$\begin{array}{lllllll}\text { Cell phone } & \text { Y } & \text { Y } & \text { Y } & \text { Y } & \text { Y }\end{array}$

Radio

Computer base station

Subscription required

Data Collection and Reports

Soil water content

Precipitation per season

Application date and depth

Irrigation events per season

Chemical application rate

Chemical application per season

System position by date

$\begin{array}{lllll}Y & Y & Y & Y & Y\end{array}$

$\begin{array}{lllll}Y & Y & Y & Y & Y\end{array}$

Y $\quad Y \quad Y \quad Y \quad-Y$

[a] $\mathrm{Y}(7)$ indicates that up to seven auxiliary components (injection pumps, endguns, etc.) can be controlled by the panel.

[b] N/Y indicates no automatic shutdown for high voltage is provided but the panel does provide automatic shutdown for low voltage.

[c] System guidance provided by above ground cable, below ground cable, furrow, or GPS

[d] Number of positions in a single revolution where speed of travel and other set points may be changed.

[e] Number of sprinkler application zones along the irrigation lateral length where water application depth can be changed.

interest in SS-VRI using center pivot and lateral move sprinkler irrigation systems. Onboard and field-distributed sensors can collect data necessary for real-time irrigation management decisions and transmit the information to the main control panel or base computer. However, the need for semi-permanent soil water monitoring sites suitable for row crop production systems has only recently been initiated and will be necessary to gain widespread acceptance. Manufacturers of center pivot and lateral move systems have long recognized the advantages of remote communication for system monitoring and control. The major manufacturers offer communication systems such as cell phones, satel- lite radios, and internet based systems that allow a manager to query the main control panel or base computer from any location at any time. This technology is largely mature and available to assist managers with operational management decisions by remote monitoring. Equipment necessary to alter water application depth to meet the management criteria for specific and relatively small management zones is now commercially available from irrigation system manufacturers and after-market suppliers that should support further development of site-specific application of water, nutrients and pesticides. However, DSS for automatic control of center pivots are largely not commercially available to irrigation managers. In addition, with the availability of SS-VRI systems for center pivots comes the need of criteria for locating data acquisition systems in the field. Alteration of the water application depth based on defined management zones will change the soil water balance during the growing season. Managers of SS-VRI systems will need criteria for deciding whether and when the water management zone map needs to be changed, and remote access and monitoring of irrigation systems will play a vital role in the commercialization of SS-VRI management.

\section{REFERENCES}

Andrade-Sanchez, P., F. J. Pierce, and T. V. Elliott. 2007. Performance assessment of wireless sensor networks in agricultural settings. ASABE Paper No. 073076. St. Joseph, Mich.: ASABE.

Beckwith, R., D. Teibel, and P. Bowen. 2004. Report from the field: Results from an agricultural wireless sensor network. In Proc. 29th Ann. IEEE International Conf. on Local Computer Networks, 471-478. S.J. Hossam Hassanein, N. Bulusu, M. Frank, A. Boukerche, and C. Hood, eds. Tampa, Fla.: IEEE Computer Society.

Buchleiter, G. W., C. Camp, R. G. Evans, and B. A. King. 2000. Technologies for variable water application with sprinklers. In Proc. 4th Decennial Nat'l Irrigation Symp., 316-321. R. G. Evans, B. L. Benham, and T. P. Trooien, eds. St. Joseph, Mich.: ASABE.

Camilli, A., C. E. Cugnasca, A. M. Saraiva, A. R. Hirakawa, and P. L. P. Correa. 2007. From wireless sensors to field mapping: Anatomy of an application for precision agriculture. Computers and Electronics Agric. 58(1): 25-36.

Camp, C. R., E. J. Sadler, D. E. Evans, L. J. Usrey, and M. Omary. 1998. Modified center pivot system for precision management of water and nutrients. Applied Eng. in Agric. 14(1): 23-31.

Chávez, J. L., F. J. Pierce, T. V. Elliot, R. G. Evans, Y. Kim, and W. M. Iversen. 2010a. A remote irrigation monitoring and control system (RIMCS) for continuous move systems. Part A: Description and development. Precision Agric. 11(1): 1-10.

Chávez, J. L., F. J. Pierce, T. V. Elliott, R. G. Evans, Y. Kim, and W. M. Iversen. 2010b. A remote irrigation monitoring and control system (RIMCS) for continuous move systems. Part B: Field testing and results. Precision Agric. 11(1): 11-26.

Chávez, J. L., F. J. Pierce, and R. G. Evans. 2010c. Compensating inherent linear move water application errors using a variable rate irrigation system. Irrig. Sci. 28(3): 203-210.

Chávez, J. L., J. L. Varble, and A. A. Andales. 2011. Performance evaluation of selected soil moisture sensors. In Proc. 23rd Central Plains Irrigation Conference, 29-38. Central Plains Irrigation Association. Available at http://www.ksre.ksu.edu/ irrigate/ OOW/P11/Chavez11.pdf. Accessed on 17 Dec. 2011. 
Coates, R. W., and M. J. Delwiche. 2008. Site-specific water and chemical application by wireless valve controller network. ASABE Paper No. 084483. St. Joseph, Mich.: ASABE.

Dowla, F. 2006. Handbook of RF and Wireless Technologies. Burlington, Mass.: Elsevier Science.

Evans, R. G., G. W. Buchleiter, E. J. Sadler, B. A. King, and G. B. Harting. 2000. Controls for precision irrigation with selfpropelled systems. In Proc. 4th Decennial Nat'l Irrigation Symp., 322-331. eds. R. G. Evans, B. L. Benham, and T. P. Trooieneds. St. Joseph, Mich.: ASABE.

Evans, R. G., S. Han, S. M. Schneider, and M. W. Kroeger. 1996. Precision center pivot irrigation for efficient use of water and nitrogen. In Proc 3rd International Conf. on Precision Agric., 75-84. P. C. Roberts, R. H. Rust, and W. E. Larsen, eds. ASACSSA.

Evans, R. G., and G. B. Harting. 1999. Precision irrigation with center pivot systems on potatoes. In Proc. ASCE 1999 International Water Resources Engineering Conf. R. Walton and R. E. Nece, eds. Reston, Va.: ASCE.

Evett, S. R., Howell, T. A., Schneider, A. D., Upchurch, D. R., and D. F. Wanjura. 1996. Canopy temperature based automatic irrigation control. In: Proc. International Conf. Evapotranspiration and Irrigation Scheduling, 207-213. C. R. Camp, E. J. Sadler, and R. E. Yoder, eds. St. Joseph, Mich.: ASABE.

Evett, S. R., R. T. Peters, and T. A. Howell. 2006. Controlling water use efficiency with irrigation automation: Cases from drip and center pivot irrigation of corn and soybean. In Proc. 28th Annual Southern Conservation Systems Conf., 57-66. R. C. Schwartz, R.L. Baumhardt, J.M.. Bell eds. Amarillo, TX: USDA-ARS Conservation and Production Research Laboratory.

Evett, S. R., R. C. Schwartz, R. J. Lascano, and M. G. Pelletier. 2010. In-soil and down-hole soil water sensors: Characteristics for irrigation management. In Proc. 5th Decennial National Irrigation Conf. M. Dukes, ed. St. Joseph, Mich.: ASABE.

Goense, D., and J. Thelen. 2005. Wireless sensor networks for precise Phytophthora decision support. ASABE Paper No. 053099. St Joseph, Mich.: ASABE.

Gowda, P. H., J. L. Chávez, P. D. Colaizzi, S. R. Evett, T. A. Howell, and J. A. Tolk. 2008. ET mapping for agricultural water management: Present status and challenges. Irrig. Sci. 26(3): 223-237.

Hebel, M. A. 2006. Meeting wide-area agricultural data acquisition and control challenges through Zigbee wireless network technology. In Proc. International Conf. Computers in Agric. and Natural Resources, 234-239. St. Joseph, Mich.: ASABE.

Hornbuckle, J., N. Car, E. Christen, T. Stein, and B. Williamson. 2009. IrriSatSMS: Irrigation water management by satellite and SMS - A utilisation framework. CSIRO Land and Water Science Report No. 04/09. Griffith, NSW, Australia: CSIRO.

IEEE802.15.1. 2005. Part 15.1: Wireless Medium Access Control (MAC) and Physical Layer (PHY) Specifications for Wireless Personal Area Networks (WPANs(tm)). New York, N.Y. : IEEE. Available at: http://standards.ieee.org/getieee802/ download/802.15.1-2005_part1.pdf. Accessed 24 July 2011.

IEEE802.15.4. 2007. Specific requirements Part 15.4: Wireless Medium Access Control (MAC) and Physical Layer (PHY) Specifications for Low-Rate Wireless Personal Area Networks (WPANs). Amendment 1: Add Alternate PHYs. New York, N.Y. : IEEE. Available at: http://standards.ieee.org/getieee802/ download/802.15.4a-2007.pdf. Accessed 24 July 2011.

Karmeli, D., and G. Peri. 1974. Basic principles of pulse irrigation. J. Irrig. Drainage Eng. 100(IR3): 309-319.
Kim, Y., and R. G. Evans. 2009. Software design for wireless sensor-based site-specific irrigation. Computers and Electronics Agric. 66(2): 159-165.

Kim, Y., R. G. Evans, and W. M. Iversen. 2007. Decision support and monitoring for wireless sensor-based site-specific sprinkler irrigation. ASABE Paper No. 073078. St. Joseph, Mich.: ASABE.

Kim, Y., R. G. Evans, and W. M. Iversen. 2008. Remote sensing and control of an irrigation system using a wireless sensor network. IEEE Trans. Instrumentation Measurement 57(7): 1379-1387.

King, B. A., and D. C. Kincaid. 2004. A variable flow rate sprinkler for site-specific irrigation management. Applied Eng. in Agric. 20(6): 765-770.

King, B. A. and L. R. Wall. 1998. Supervisory control and data acquisition system for site-specific center pivot irrigation. Applied Eng. in Agric. 14(2): 135-144.

King, B. A., R. W. Wall, and L. R. Wall. 2000. Supervisory control and data acquisition system for closed-loop center pivot irrigation. ASABE Paper No. 002020. St. Joseph, Mich.: ASABE.

Lamm, F. R., and R. M. Aiken. 2008. Comparison of temperaturetime threshold and ET-based irrigation scheduling for corn production. ASABE Paper No. 084202. St. Joseph, Mich.: ASABE.

Lee, W. S., T. F. Burks, and J. K. Schueller. 2002. Silage yield monitoring system. ASABE Paper No. 021165. St. Joseph, Mich.: ASABE.

Liang, Q., D. Yuan, Y. Wang, and H. H. Chen. 2007. A cross-layer transmission scheduling scheme for wireless sensor networks. Computer Comm. 30(14-15): 2987-2994.

Lyle, W. M., and J. P. Bordovsky. 1981. Low energy precision application (LEPA) irrigation system. Trans. ASABE 26(5): 1241-1245.

Mahan, J. R., W. Conaty, J. Neilsen, P. Payton, and S. B. Cox. 2010. Field performance in agricultural settings of a wireless temperature monitoring system based on a low-cost infrared sensor. Computers and Electronics Agric.71(2): 176-181.

McCarthy, A. C., N. H. Hancock, and S. R. Raine. 2010. VARIwise: A general-purpose adaptive control simulation framework for spatially and temporally varied irrigation and sub-field scale. Computers and Electronics Agric. 70(1): 117-128.

Miranda, F. R., R. Yoder and J. B. Wilkerson. 2003. A site-specific irrigation control system. ASABE Paper No. 031129. St. Joseph, Mich.: ASABE.

Oksanen, T., M. Ohman, M. Miettinen, and A. Visala. 2004. Open configurable control system for precision farming. ASABE Paper No. 041004. St. Joseph, Mich.: ASABE.

O'Shaughnessy, S. A., and S. R. Evett. 2010. Developing wireless sensor networks for monitoring crop canopy temperature using a moving sprinkler system as a platform. Applied Eng. in Agric. 26(2):331-341.

Perry, C. D., M. D. Dukes, and K. A. Harrison. 2004. Effects of variable-rate sprinkler cycling on irrigation uniformity. ASABE Paper No. 041117. St. Joseph, Mich.: ASABE.

Peters, R. T., and S. R. Evett. 2004. Modeling diurnal canopy temperature dynamics using one-time-of-day measurements and a reference temperature curve. Agron. J. 96(6): 1553-1561.

Peters, R. T., and S. R. Evett. 2005. Using low-cost GPS receivers for determining field position of mechanical irrigation systems. Applied Eng. in Agric. 21(5):841-845.

Peters, R. T., and S. R. Evett. 2007. Spatial and temporal analysis of crop stress using multiple canopy temperature maps created with an array of center-pivot-mounted infrared thermometers. Trans. ASABE 50(3): 919-927. 
Peters, T. R., and S. R. Evett. 2008. Automation of a center pivot using the temperature-time threshold method of irrigation scheduling. J. Irrig. Drainage Engr. 134(1): 286-291.

Pierce, F. J., and T. V. Elliott. 2008. Regional and on-farm wireless sensor networks for agricultural systems in eastern Washington. Computers and Electronics Agric. 61(1): 32-43.

Roth, R. L., and B. R. Gardner. 1989. Modified self-moving irrigation system for water-nitrogen crop production studies. ASABE Paper No. 890502. St. Joseph, Mich.: ASABE.

Sadler, E. J., R. G. Evans, K. C. Stone, and C. R. Camp. 2005. Opportunities for conservation with precision irrigation. J. Soil and Water Cons. 60(6): 371-379.

Sadler, E. J., R. G. Evans, G. W. Buchleiter, B. A. King, and C. R. Camp. 2000. Site-specific irrigation - management and control. In Proc. 4th Decennial Nat'l Irrigation Symp., 304-315. R. G. Evans, B. L. Benham, and T. P. Trooien, eds. St. Joseph, Mich.: ASABE.
Shock, C. C., R. J. David, C. A. Shock, and C.A. Kimberling. 1999. Innovative, automatic, low-cost reading of Watermark soil moisture sensors. In Proc. 1999 Irrigation Association Technical Conf., 147-152. Falls Church, Va.: Irrigation Association.

Upchurch, D. R., D. F. Wanjura, J. J. Burke, and J. R. Mahan. 1996. Biologically-Identified Optimal Temperature Interactive Console (BIOTIC) for managing irrigation. U.S. Patent No. 5539637.

Vellidis, G., M. Tucker, C. Perry, C. Kvien, and C. Bednarz. 2008. A real-time wireless smart sensor array for scheduling irrigation. Computers and Electronics Agric. 61(1): 44-50.

Wall, R. W., and B.A. King. 2004. Incorporating plug and play technology into measurement and control systems for irrigation management. ASABE Paper No. 042189. St. Joseph, Mich.: ASABE.

Zhang, Z. 2004. Investigation of wireless sensor networks for precision agriculture. ASABE Paper No. 041154. St. Joseph, Mich.: ASABE. 